\title{
Decomposition in HTPB bonded HMX followed by heat generation rate and chemiluminescence
}

\author{
F. Käser · M. A. Bohn
}

Received: 15 April 2009/Accepted: 4 May 2009/Published online: 19 June 2009

(c) Akadémiai Kiadó, Budapest, Hungary 2009

\begin{abstract}
The decomposition in HTPB bonded HMX was characterized with two highly sensitive methods: heat flow microcalorimetry (HFMC) and Chemiluminescence (CL). The material is stabilized with a phenolic antioxidant. The heat generation (HFMC) rate was determined from 120 to $150{ }^{\circ} \mathrm{C}$ using a $\mathrm{TAM}^{\mathrm{TM}}$ microcalorimeter and the oxidation of the substance was followed by the CL emission between 100 and $140{ }^{\circ} \mathrm{C}$ directly from the solid state sample. The end of antioxidant activity results in both measurements sets in characteristic changes in the curves. Kinetic parameters were calculated applying Arrhenius parameterization for the times to the end of antioxidant activity and by applying modelling with an autocatalytic model extended by a side reaction, which is assigned to the antioxidant consumption. The evaluation with the characteristic times gives good agreement between the two methods; the modelling represents the different but supplementing probing of the two measurement methods.
\end{abstract}

Electronic supplementary material The online version of this article (doi:10.1007/s10973-009-0031-6) contains supplementary material, which is available to authorized users.

\section{F. Käser $(\bowtie)$}

ACL Instruments AG, P.O. Box 10, Industriestr. 11, 3210

Kerzers, Switzerland

e-mail: fabian.kaeser@aclinstruments.com

F. Käser

Berne University of Applied Sciences, Fellerstr. 11, 3027 Berne, Switzerland

\section{A. Bohn}

Fraunhofer-Institut für Chemische Technologie (ICT), Postfach 1240, 76318 Pfinztal-Berghausen, Germany
Keywords HTPB bonded HMX - Microcalorimetry · Heat generation rate - Chemiluminescence - Oxidation . Kinetic parameter analysis

\section{Introduction}

Microcalorimetric analytical methods are very sensitive in monitoring the heat generation rate during the decomposition of energetic materials. High sensitivities in the $\mu \mathrm{W}$ range enable the detection of the early decomposition stages, i.e. reaction progress levels ranging from 0 to $5 \%$ (conversion alpha $=0.00$ to 0.05 ) [1]. The benefit of these methods is the moderate temperature conditions at investigation comparable to the in-service temperature conditions. Due to the exponential temperature dependence of the reaction rate, long measuring times are necessary at moderate temperature profiles to get reliable results. This fact cannot be annulled, but often it is tried to ignore it. The prediction of in-service time periods become more accurate, the closer the temperature of in-use or storage and investigation are. To determine reliable data at lower temperatures needs stable and sensitive measuring methods as Heat Flow Microcalorimetry (HFMC), which has been applied successfully to evaluate stabilizers for advanced systems [2, 3] and in assessing new energetic materials [4-6].

It is well known that most of the organic materials readily react with oxygen even at ambient temperatures. This oxidative degradation is a severe material-engineering problem. Monitoring and predicting the stability of organic materials against oxidation is therefore of paramount importance in view of stability, safety and guarantee purposes. Commonly applied analytical methods to analyse long term oxidation behaviour of organic solids with low 
sensitivity as Differential Scanning Calorimetry require the investigation at higher temperatures. Such conditions may invoke reaction pathways which are different from those encountered under the conditions of use. Decomposition processes and especially the oxidation decay leading to the failure of the substances can be overseen even for years. But once the reaction has reached a critical stage, it proceeds in rapid, autocatalytic acceleration and leads to unexpected failure. In such a situation, alternative methods based on investigations carried out at low temperatures or with high sensitivity should be applied for the characterisation of the long-term stability of organic substances. Besides HFMC the Chemiluminescence (CL) method can be employed with suitable equipment as very sensitive measuring method.

The following results represent the first stage of research by using the Chemilumines-cence method to characterise decompositions reactions of energetic materials in combination with microcalorimetric measurements.

\section{Substances}

The material investigated is an example of a high explosive charge (HEC). The essential components are HMX (Octogen) and a binder of polyurethane type. This binder consists of HTPB (hydroxyl terminated polybutadiene) crosslinked with isophorone diisocyanate. Typically the HMX content varies between 80 and 90 mass-\%. Because polybutadiene is sensitive to oxygen attack, phenolic antioxidants are commonly added. The oxygen attack on the HTPB backbone is favored in the allylic position HC$\mathrm{C}=\mathrm{C}$ because of resonance stabilization of the radical function. With two radical functions on neighboring chains cross-linking can occur and elasticity is reduced. For this work a formulation was used which contains 85 mass- $\%$ HMX bonded by HTPB-binder, which additionally contains some plasticizer and a phenolic antioxidant of about 0.1 mass-\%. It is called in the following HEC or in short HMX-HTPB.

\section{Measurement methods}

Heat flow microcalorimetry

The heat generation rate (HGR) of HMX and HTPB bonded HMX (=HEC, high explosive charge) was measured with a so named high temperature $\mathrm{TAM}^{\mathrm{TM}}$ (Thermal Activity Monitor), model type II, produced by Thermometric AB, Sweden, now belonging to Waters Inc., BU TA Instruments. The measurement temperature range is from 15 up to $150{ }^{\circ} \mathrm{C}$. It is equipped with four microcalorimeter inserts (four channels) immersed in a highly temperature constant silicon oil bath. The working principle is of twin type to reduce the temperature fluctuations of the bath by a thermally balanced reference mass. The baseline stability of these TAM II instruments is very high, and this over weeks. Measurement ampoules up to $4 \mathrm{~mL}$ volume can be used. For the measurements Hastelloy ${ }^{\mathrm{TM}}-\mathrm{C} 22$ ampoules, obtained from Thermometric $\mathrm{AB}$, have been used in order to withstand the expected higher gas pressures caused by the decomposition of HEC. The ampoules are closed by screw caps using a thin Teflon ${ }^{\mathrm{TM}}$ disk as squeezing seal. Estimated gas pressures ranged up to 50 bars, which the ampoules can still handle also at $150{ }^{\circ} \mathrm{C}$. The sample was weighed-in into small Duran ${ }^{\mathrm{TM}}$ glass vials inserted into the ampoules to avoid contact between metal and HEC. The amount applied was adjusted to have maximum sample mass (=measurement sensitivity) and safety against ampoule opening. Sample masses were in the range of 1.0 $1.2 \mathrm{~g}$ (loading densities from $0.31-0.37 \mathrm{~g} \mathrm{~mL}^{-1}$ ). HGR measurements have been performed between 120 and $150{ }^{\circ} \mathrm{C}$.

\section{Chemiluminescence}

Luminescence is a term used for various phenomena, originating from electronically excited states. The emission of photons results from the relaxation of excited electrons (triplet-state) into their ground-state. Chemiluminescence includes all Luminescence phenomena resulting from chemical reactions [7]. The fact that organic substances undergoing oxidation emit light has been recognized already at the second half of XIX century [8]. Meanwhile Chemiluminescence has gained wide acceptance as a sensitive method to study the oxidative degradation of organic solid substances [10-12].

The emission of light during the oxidative degradation process of the organics is a part of the reaction course. The first step in the oxidative degradation is the formation of unstable alkyl radicals, which immediately scavenge the oxygen from the atmosphere or from oxygen already migrated into the sample to form peroxy radicals. These react further and transform into different species in an accelerating degradation cycle (auto-oxidation, left part of Fig. 1. It is normally attributed to a transition of excited triplet-carbonyl-function $\left({ }^{3} \mathrm{R}=\mathrm{O} *\right)$ into its ground state. The spectral range of this emitted light varies according to the type of substances involved. In most cases the Chemiluminescence is observed in the short wave region of the visible spectrum from 380 to $450 \mathrm{~nm}$.

Compared to the other conventional thermo-analytical methods, CL offers many ad-vantages: due to its outstanding sensitivity, experiments can be performed at low temperatures i.e. closer to the application related 


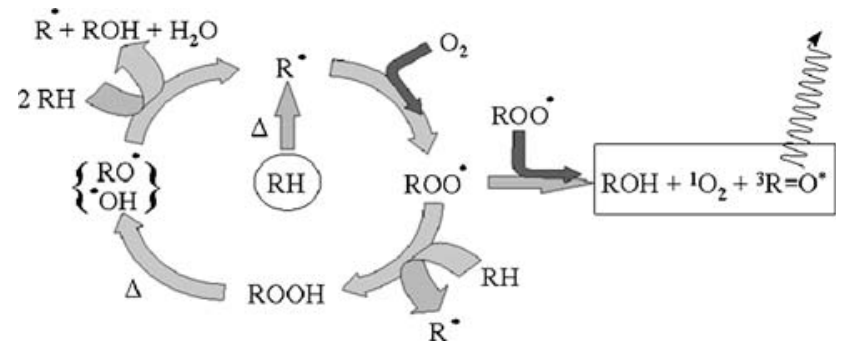

Fig. 1 Simplified scheme of auto-oxidation of organics (from Lacey et al. [13]: the combination of two peroxy radicals with a concomitant fragmentation in a Russel mechanism [14] is strongly exothermal $\left(460 \mathrm{~kJ} \mathrm{~mole}^{-1}\right)$ [15]. The CL-emitter is an excited "triplet" carbonyl function ${ }^{3} \mathrm{R}=\mathrm{O}^{*}$

conditions. This fact is of importance for the characterisation of substances with low temperature melting points, glass transitions, etc. The baseline stability of CL is of great benefit when performing long-term experiments [16]; moreover the CL-signal is related exclusively to the oxidation processes and therefore is not superposed by the signals resulting from the other reactions, including phase transitions. The instrumentation setup may be designed individually for special fields of applications and goals of research. The experiments can be performed with the sample masses as low as approx. $0.1 \mathrm{mg}$.

The instrumentations provided by ACL Instruments are fully automated and consist of cooled PMT (photo multiplier tube) with photon counting mode in combination with an optical path including a shutter system, to protect the highly sensitive detection unit against extensive light during sample handling and to provide background measurements. The data acquisition of the following Chemiluminescence experiments was performed using the basic instrument configuration without any extension modules, produced by ACL Instruments Inc., Switzerland (http:// www.aclinstruments.com). The measurement temperature range is $20{ }^{\circ} \mathrm{C}$ to $200{ }^{\circ} \mathrm{C}$. The flow of the synthetic air was $30 \mathrm{ml} \mathrm{min}{ }^{-1}$. The instrument is equipped with a passivated silver oven cell for precise temperature control. The CLemission is guided through an optical pathway to the photomultiplier tube operating in the photon counting mode. Glass crucibles provided by ACL Instruments have been used in order to prevent sample's contamination by catalytic active transition metals $(\mathrm{Cu}, \mathrm{Fe}$ etc.) usually present in aluminium crucibles. The here applied sample amounts have been: 44, 28, 34, 22 and $14 \mathrm{mg}$ at 100, 110, 120, 130 and at $140{ }^{\circ} \mathrm{C}$, respectively. The sample geometry must be very similar to obtain comparable data.

\section{Measurement results}

\section{Heat generation rate measurements}

In Fig. 2 the measurements of heat generation rates (HGR, $\mathrm{dQ} \mathrm{dt}^{-1}$ ) and the calculated heat generations (HG, Q) of HEC are shown at $120^{\circ} \mathrm{C}$ in air and in argon. The differences in HGR and HG caused by the two atmospheres are very pronounced at the beginning. One can conclude that the oxidising atmosphere has an influence on the measured signals. After the sharp bend in HGR under air the HGR under argon has similar values, but still somewhat lower than under air. The main difference in $\mathrm{HG}$ is caused by the contribution up to about 3.3 days at $120^{\circ} \mathrm{C}$. It is assigned to the reaction of the antioxidant in the material. Also at all other measurement temperatures the same effect was found. It is already recognizable that HGR increases with time indicating a starting auto-acceleration in the decomposition. But also under argon this effect appears but somewhat retarded to the situation under air. It seems there is a decomposition component going on independently of the oxidising or non-oxidising atmosphere.
Fig. 2 Heat generation rate (HGR/dQ dt ${ }^{-1}$ ) and heat generation (HG/Q) of HEC (HMX-HTPB) at $120^{\circ} \mathrm{C}$ in air and in argon. The influence of the oxidising atmosphere is very clearly recognizable. Especially at the beginning the decrease of HGR in argon is much faster than in air. The HGR curves of HEC in air show a sharp bend at about 3.2 days

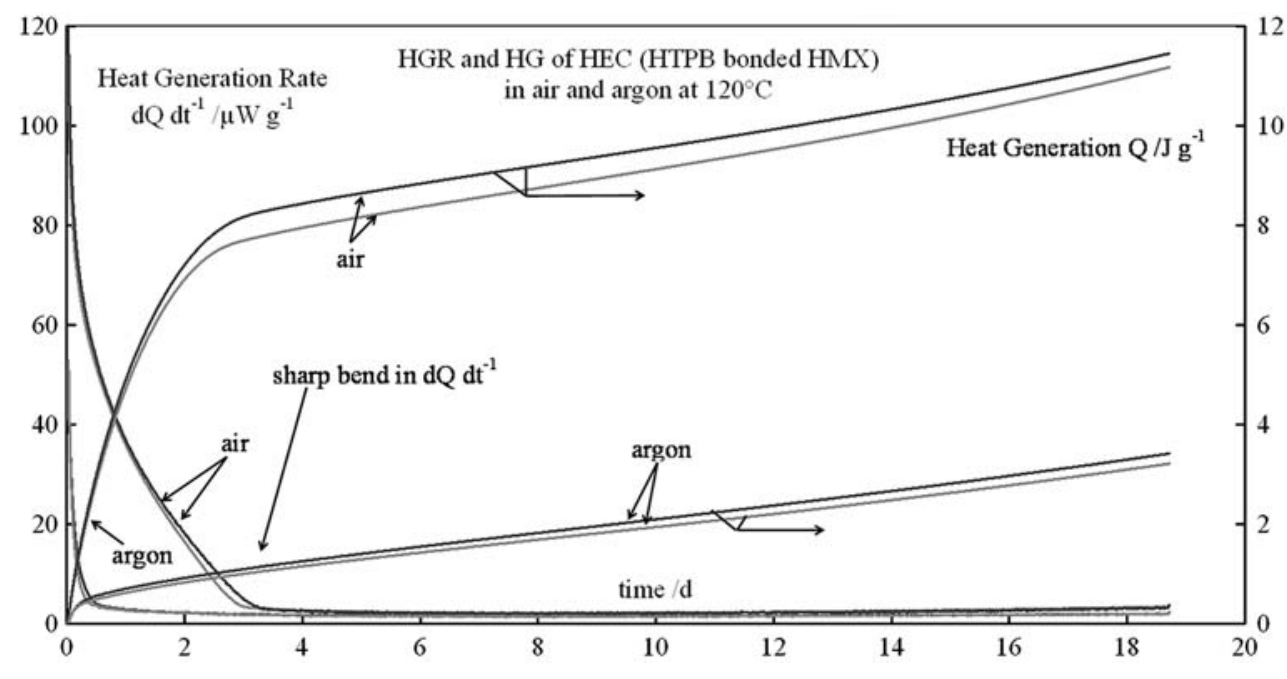


Fig. 3 Reaction progress of the oxidation of HTPB in the HEC followed by

Chemiluminescence in synthetic air as function of temperature and time. Shown are the Chemiluminescence intensity $\left(\right.$ cts s$^{-1} \mathrm{mg}^{-1}$ ) and the integrated CL intensity $\left(\right.$ cts $\left.\mathrm{mg}^{-1}\right)$. Time axis is logarithmically scaled

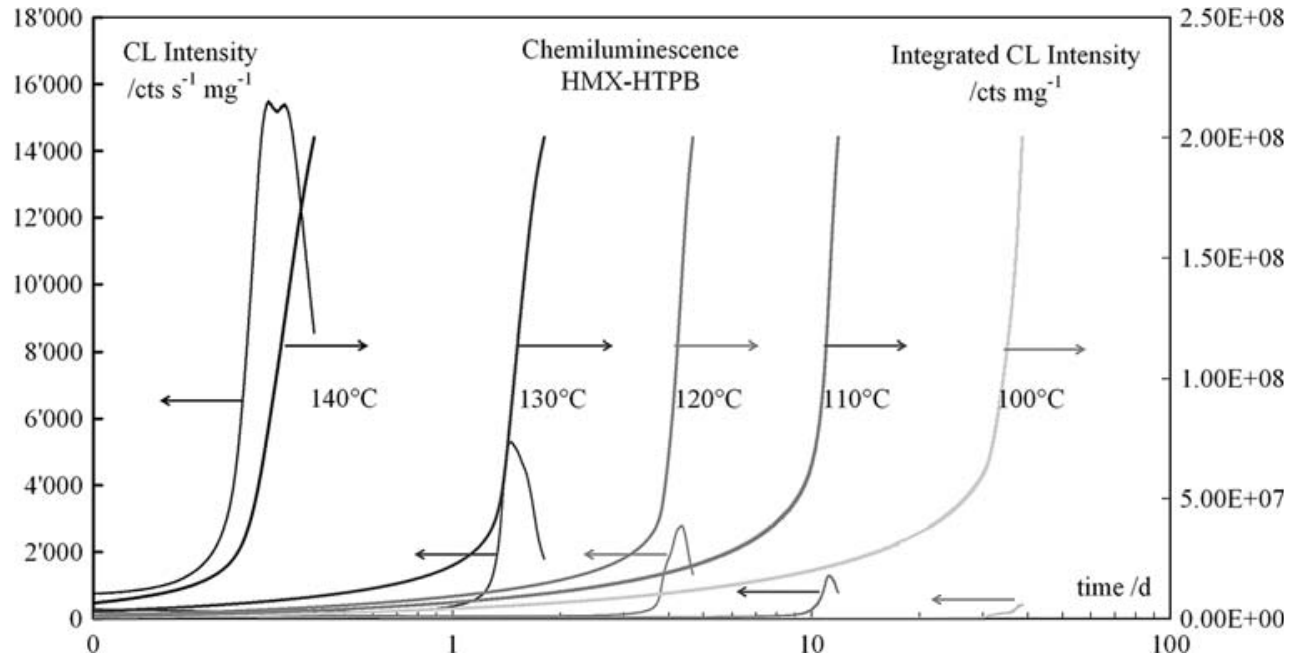

The HGR and HG values of pure HMX are significantly lower than the ones of the HEC. Further the HGR of HMX stays quite low and nearly non-acceleratory over much longer time periods, during which the HGR of HEC has reached definitely the autocatalytic decomposition.

\section{Chemiluminescence measurements}

The Chemiluminescence measurements have been performed at 100,110,120, 130 and $140{ }^{\circ} \mathrm{C}$. A selection of the data can be seen in Fig. 3 with time axis in logarithmic scaling.

The Chemiluminescence signal of pure HMX measured at $140{ }^{\circ} \mathrm{C}$ is lower than one order of magnitude compared to the values of the HEC; it seems that the pure HMX is not undergoing oxidation during the performed Chemiluminescence experiments during the here applied time periods.

\section{Data evaluation}

Using characteristic phenomena of the measured curves

As already seen above, the curves of $H G R$ and CL-rate show some characteristic effects, which may be attributed to a change in reaction behaviour, here the change from stabilized HEC to unstabilized HEC in the sense of consumption of antioxidant (AO). Therefore the times until to these characteristic points can be used to get information about the Arrhenius parameters of antioxidant consumption, which in turn can be used to calculate the times $t_{k}$ until $\mathrm{AO}$ consumption at further temperatures with Eq. 1.
$t_{k}(T)=\frac{1}{Z_{k}} \cdot \exp \left(+E a_{k} / R T\right)$

To determine the characteristic time of the bend in the HGR curves and the onset time of the auto-oxidation in CL curves, the commonly applied tangential method was used.

In Table 1 these characteristic times have been compiled together with logarithmic rates and the corresponding Arrhenius parameters. From the CL-data two sets of Arrhenius parameters have been calculated differing in the used temperature range as indicated. The somewhat greater activation energies found from the CL-data result in longer times near ambient temperatures. This is not critical, because the higher temperatures up to $70{ }^{\circ} \mathrm{C}$ are more important for the assessment in real theatre environments.

Figure 4 depicts the Arrhenius diagram for the rate constants obtained from both characteristic times, defined as the reciprocal of the times. These characteristic times represent the total consumption of the AO.

Kinetic modelling of the measured curves: reaction scheme of auto-oxidation by oxygen

Oxygen is a biracial molecule, ${ }^{\bullet} \mathrm{O}=\mathrm{O}^{\bullet}$ attacking organic matter even at normal ambient temperatures. If special structural elements are present in the molecules as $\mathrm{C}-\mathrm{C}$ double bond or ether groups the oxygen attack is fostered greatly. The name auto-oxidation is given to the autocatalytic oxidation of organic materials by molecular oxygen. To prevent the degradation or even destruction of the material so-called antioxidants are added. Several types have been developed and commonly used types are phenolic antioxidants. The basic radical reactions occurring in oxygen degradation may be grouped according to their characteristics. 
Table 1 Times $t_{\text {kdQ }}$ until the sharp bend in HGR curves and times $\mathrm{t}_{\mathrm{kCL}}$ until the strong increase in CL-rate of HEC as well as the corresponding logarithmic rates and the Arrhenius parameters derived

\begin{tabular}{|c|c|c|c|c|}
\hline \multirow[t]{2}{*}{$T /{ }^{\circ} \mathrm{C}$} & \multicolumn{2}{|c|}{ HGR curves $\mathrm{dQ} / \mathrm{dt}$} & \multicolumn{2}{|l|}{ CL-rate curves } \\
\hline & $\operatorname{Ln}\left[1 / t_{k d Q}\right] / d^{-1}$ & $\mathrm{t}_{\mathrm{kdQ}} / \mathrm{d}$ & $\operatorname{Ln}\left[1 / t_{k C L}\right] / \mathrm{d}^{-1}$ & $t_{k C L} / \mathrm{d}$ \\
\hline 100 & - & - & 0.033557 & 29.8 \\
\hline 110 & - & - & 0.101112 & 9.89 \\
\hline 120 & -1.164712 & 3.205 & 0.272479 & 3.67 \\
\hline 120 & -1.234017 & 3.435 & - & - \\
\hline 130 & -0.285179 & 1.33 & 0.769823 & 1.299 \\
\hline 130 & -0.381855 & 1.465 & - & - \\
\hline 135 & 0.088831 & 0.915 & - & - \\
\hline 135 & 0.032523 & 0.968 & - & - \\
\hline 140 & 0.605136 & 0.546 & (1.452434) not used & 0.234 \\
\hline 140 & 0.549913 & 0.577 & - & - \\
\hline 145 & 1.114742 & 0.328 & - & - \\
\hline 145 & 1.072945 & 0.342 & - & - \\
\hline 150 & 1.491655 & 0.225 & - & - \\
\hline 150 & 1.366492 & 0.255 & - & - \\
\hline$E a_{k} / \mathrm{kJ} \mathrm{mol}^{-1}$ & $123.7 \pm 3$ & & $130.0 \pm 2$ & \\
\hline $\operatorname{Lg}\left[Z_{k}\right] / d^{-1}$ & $15.896 \pm 037$ & & $16.715 \pm 0.22$ & \\
\hline$R^{2}$ & 0.9946 & & 0.9997 & \\
\hline
\end{tabular}

Fig. 4 Arrhenius diagram of reciprocal times $t_{k d Q}$ until occurrence of the sharp bend in HGR curves (solid line) and times $t_{k C L}$ until occurrence of the strong increase in CL-rate of HEC (broken line)

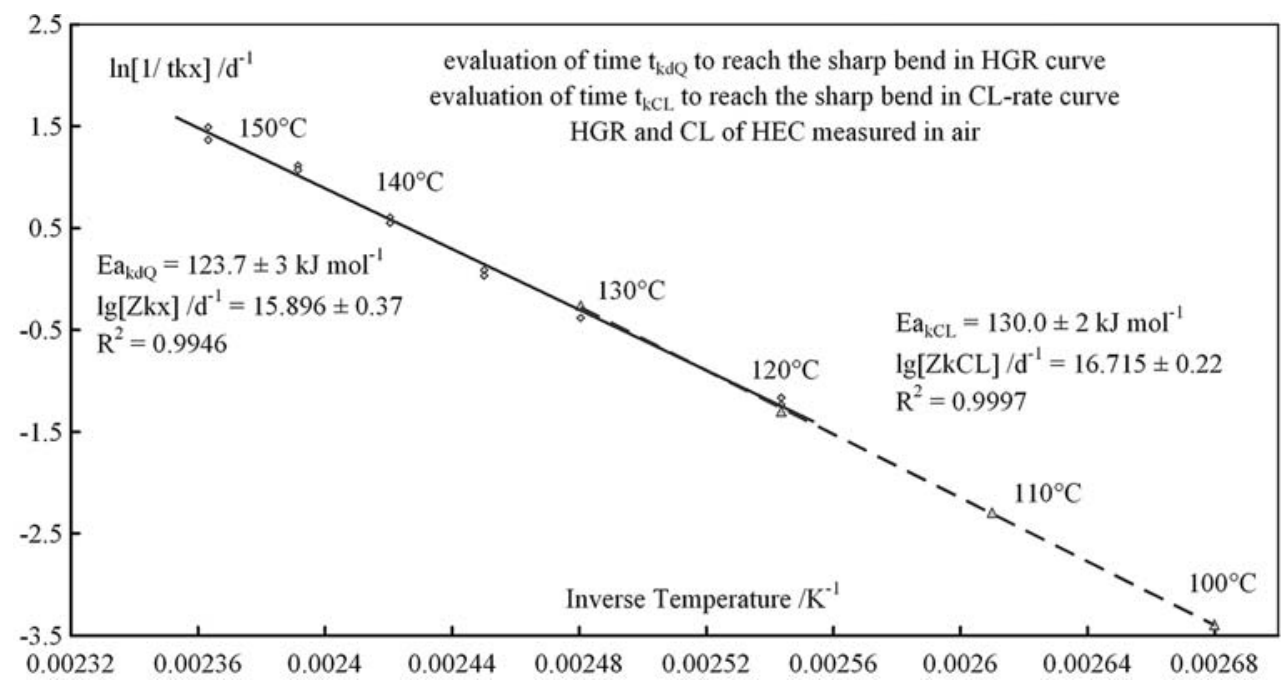

- Start: radical formation at binder material

- Chain propagation: forms further radical sites at binder

- Chain branching: increase of autocatalytical activity

- Chain termination: consumption of formed and attacking species but not of oxygen.

- Stabilization: radical neutralization by antioxidant

- Promotion of auto-oxidation by catalytic active transition metals

Because heat generation rate curves and Chemiluminescence curves alone provide to less information to handle all reaction sequences one must reduce the scheme in such a way that the main characteristic is maintained. Main characteristic elements are:
- Oxidative attack of the binder or any organic material

- Formation of autocatalytic effective species B, radical in type

- Attack of radical B on the binder

- The effect of antioxidant AO in neutralizing the radical $B$

These elements must be expressed in a model.

Kinetic modelling of the measured curves: approx. modelling by autocatalytic reaction scheme

Both measurement methods have revealed auto-accelerating reaction behaviour of the HEC. This should be modelled by 
kinetic formulations containing autocatalytic characteristic. The basic autocatalytic model was already described and used for energetic materials [4, 17]. Recently it was applied also to describe the behaviour of guanylurea dinitramide (GUDN) [5]. The aim is to find approximated models which describe the data, as explained in the following. The model formulation starts with an autocatalytic reaction scheme [3]. Substance A decomposes in gases $\mathrm{C}$, in solids $\mathrm{S}$ and in an autocatalytic effective product $\mathrm{B}$. In the second parallel reaction $\mathrm{B}$ reacts with $\mathrm{A}$ and accelerates its consumption.

$\mathrm{A} \stackrel{k_{1}}{\rightarrow} \mathrm{B}+\mathrm{C}+\mathrm{S} \quad\left(-\Delta H_{R, 1}\right)$

intrinsic decomposition

$\mathrm{A}+\mathrm{B} \stackrel{k_{2}}{\rightarrow} 2 \mathrm{~B}+\mathrm{C}+\mathrm{S} \quad\left(-\Delta H_{R, 2}\right)$

autocatalytic decomposition

The intrinsic decomposition of A can not be suppressed by stabilizers. With stabilizers only the autocatalytic reaction can be influenced by removing $\mathrm{B}$ by chemically bonding it to the stabilizing substance. In Eq. 3 the intrinsic or inherent decomposition of $\mathrm{A}$ is included as first order reaction. resulting hydroperoxide radical is an effective agent in attacking the HEC. This behaviour can be approximated by reaction scheme Eq. 4.

$\mathrm{A}+\mathrm{Ox} \stackrel{k_{1}}{\rightarrow} \mathrm{B}+\mathrm{C}+\mathrm{S} \quad\left(-\Delta H_{R, 1}\right)$

(intrinsic) decomposition

$\mathrm{A}+\mathrm{B} \stackrel{k_{2}}{\rightarrow} 2 \mathrm{~B}+\mathrm{C}+\mathrm{S} \quad\left(-\Delta H_{R, 2}\right)$

autocatalytic decomposition

$\mathrm{AO}+\mathrm{B} \stackrel{k o}{\rightarrow} \mathrm{AO}-\mathrm{B} \quad\left(-\Delta H_{R, S}\right)$

stabilizing reaction

In part some side reaction can occur, especially at higher temperatures, which are neglected here. The concentration of incoming oxygen is assumed as constant, which is especially true with the CL measurements because of the constant flow purging by synthetic air. This gives a pseudofirst order reaction for the first decomposition step. The approximated formulation of the models based on Eq. 4 are given in Eqs. 5 and 6 to describe the heat generation $\mathrm{Q}$ and the Chemiluminescence intensity I-CL, respectively.

$Q(t, T)=O F_{Q}+Q(t e) \cdot\left\{\begin{array}{l}a \cdot\left(1-\exp \left(-k_{Q o} \cdot t\right)\right) \ldots \\ \ldots+(1-a) \cdot\left(1-\frac{k_{Q 1}(T)+k_{Q 2}(T)}{k_{Q 2}(T)+k_{Q 1}(T) \cdot \exp \left(\left(k_{Q 2}(T)+k_{Q 2}(T)\right) \cdot t\right)}\right)\end{array}\right\}$

$I c(t, T)=O F_{C L}+I c(t e) \cdot\left\{\begin{array}{l}a \cdot\left(1-\exp \left(-k_{C L o} \cdot t\right)\right) \ldots \\ \ldots+(1-a) \cdot\left(1-\frac{k_{C L 1}(T)+k_{C L 1}(T)}{k_{C L 2}(T)+k_{C L 1}(T) \cdot \exp \left(\left(k_{C L 1}(T)+k_{C L 2}(T)\right) \cdot t\right)}\right)\end{array}\right\}$

$$
\left.\left(\frac{d A(t, T)}{d t}\right)\right|_{T}=-k_{1}(T) \cdot A(t, T)-k_{2}(T) \cdot A(t, T) \cdot B(t, T)
$$

With the HEC used here we have a pronounced reaction characteristic before the autocatalytic reaction starts. This is caused by some oxygen attack on A = HEC and by the stabilizer, an antioxidant (AO) which suppresses the autocatalytic cycle. The first, in part still intrinsic reaction is only limited mitigated, because the antioxidant cannot fully neutralize incoming oxygen. If the oxygen reacts with the $\mathrm{AO}$ in its typical way as $\mathrm{H}$-donor, no neutralization of oxygen effect is achieved because the
In Fig. 5 the application of the two model forms can be seen to describe heat generation Q and integrated CL-rate of HEC.

To find the fit parameters of the models a commercial programme package was used, which allows non-linear parameter adjustment and the application of user defined equations [18]. Table 2 lists the three reaction rate constants obtained by the modelling of the integrated CL-rate $\mathrm{I}_{\mathrm{C}}$ and the determined Arrhenius parameters, together with some assessment parameters for the parameter adjustment. In Table 3 the Arrhenius parameters are given of the analogous set of reaction rate constants for the description of the heat generation of HEC. 
Fig. 5 Example of the description of the heat generation and

Chemiluminescence of HEC obtained at $130{ }^{\circ} \mathrm{C}$ under synthetic air (black curves). Model (grey curves): 'Q: main: first order + autocatalytic: minor: exponential'

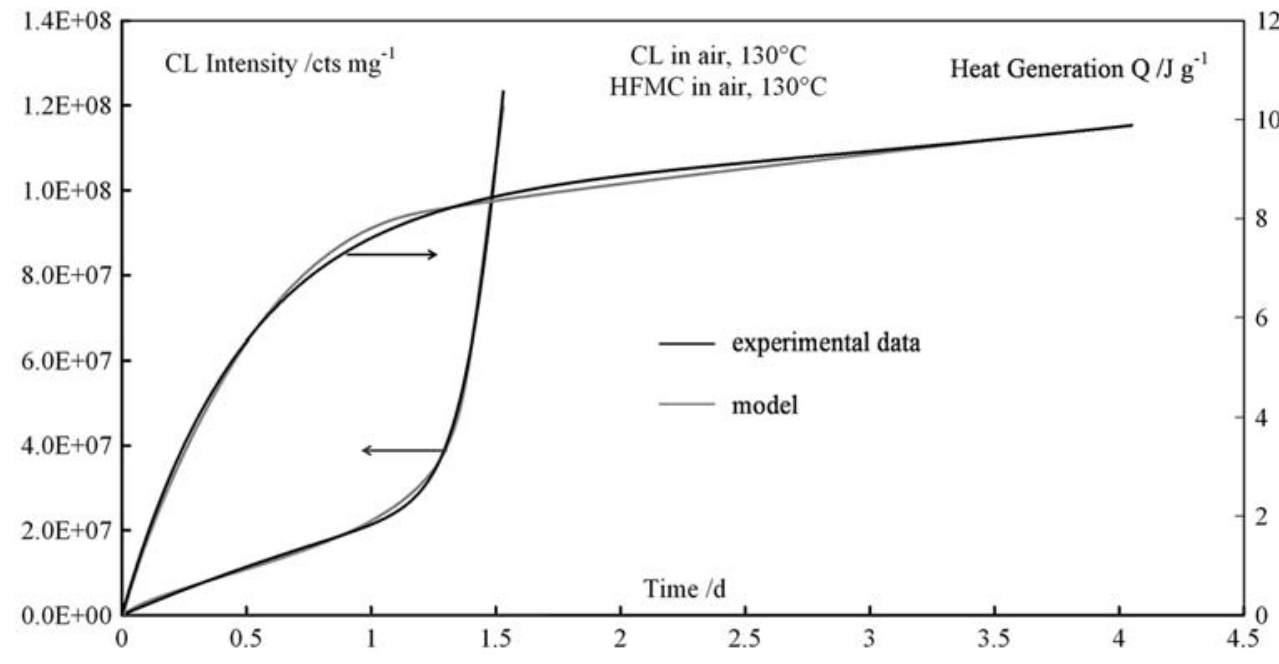

Table 2 Measurements of CL performed under synthetic air

\begin{tabular}{|c|c|c|c|c|c|c|}
\hline$T /{ }^{\circ} \mathrm{C}$ & $k_{C l} / \mathrm{d}^{-1}$ & $k_{C 2} / \mathrm{d}^{-1}$ & $k_{C o} / \mathrm{d}^{-1}$ & $a /-$ & $R^{2} /-$ & $S D^{2} /\left(\text { cts } \mathrm{mg}^{-1}\right)^{2}$ \\
\hline 100 & $1.1043 \mathrm{E}-8 \pm 1.2 \mathrm{E}-9$ & $4.7355 \mathrm{E}-1 \pm 3.2 \mathrm{E}-3$ & $4.8327 \mathrm{E}-2 \pm 6.5 \mathrm{E}-4$ & 0.2 & 0.9832 & $1.41 \mathrm{E}+13$ \\
\hline 110 & 3.8915 E- $8 \pm 3.0$ E-9 & $1.5211 \mathrm{E}+0 \pm 7.5 \mathrm{E}-3$ & $1.1322 \mathrm{E}-1 \pm 2.2 \mathrm{E}-3$ & 0.2 & 0.9961 & $7.61 \mathrm{E}+12$ \\
\hline 120 & 4.6630 E- $8 \pm 2.4$ E-9 & $4.1682 \mathrm{E}+0 \pm 1.4 \mathrm{E}-2$ & $1.6558 \mathrm{E}-1 \pm 2.9 \mathrm{E}-3$ & 0.2 & 0.9993 & $9.35 \mathrm{E}+11$ \\
\hline 130 & $1.4238 \mathrm{E}-6 \pm 1.2 \mathrm{E}-7$ & $10.025 \mathrm{E}+0 \pm 6.8 \mathrm{E}-2$ & $4.2075 \mathrm{E}-1 \pm 2.1 \mathrm{E}-2$ & 0.2 & 0.9984 & $9.59 \mathrm{E}+11$ \\
\hline 140 & $6.5538 \mathrm{E}-4 \pm 4.9 \mathrm{E}-5$ & $31.609 \mathrm{E}+0 \pm 4.3 \mathrm{E}-1$ & $1.1512 \mathrm{E}+0 \pm 1.9 \mathrm{E}-1$ & 0.2 & 0.9994 & $7.32 \mathrm{E}+10$ \\
\hline$E a_{C X} / \mathrm{kJ} \mathrm{mol}^{-1}$ & $206.2 \pm 21$ & $131.9 \pm 3.5$ & $97.8 \pm 9.2$ & & & \\
\hline $\operatorname{Lg}\left[Z_{C x}\right] / d^{-1}$ & $20.824 \pm 2.80$ & $18.137 \pm 0.47$ & $12.337 \pm 1.22$ & & & \\
\hline$R^{2} /-$ & 0.9899 & 0.9979 & 0.9743 & & & \\
\hline$S D^{2} /\left(\mathrm{d}^{-1}\right)^{2}$ & 0.128 & 0.0753 & 0.0511 & & & \\
\hline
\end{tabular}

Reaction rate constants and Arrhenius parameters for the integrated CL rate Ic obtained with model 'CL: main: first order + autocatalytic; minor: exponential'; $\mathrm{Ic}(\mathrm{te})=3.0 \mathrm{E}+8 \mathrm{cts} \mathrm{mg}^{-1}$, description range from 0 to about $1.5 \mathrm{E}+8$ to $2.0 \mathrm{E}+8 \mathrm{cts} \mathrm{mg}^{-1}$

Table 3 Part of the HGR measurements under air

\begin{tabular}{|c|c|c|c|c|c|c|}
\hline $\mathrm{T} /{ }^{\circ} \mathrm{C}$ & $k_{C L 1} / \mathrm{d}^{-1}$ & $k_{C L 2} / \mathrm{d}^{-1}$ & $k_{C L o} / \mathrm{d}^{-1}$ & $a /-$ & $R^{2} /-$ & $S D^{2} /\left(\text { cts } \mathrm{mg}^{-1}\right)^{2}$ \\
\hline 100 & 1.1043 E- $8 \pm 1.2$ E-9 & $4.7355 \mathrm{E}-1 \pm 3.2 \mathrm{E}-3$ & $4.8327 \mathrm{E}-2 \pm 6.5 \mathrm{E}-4$ & 0.2 & 0.9832 & $1.41 \mathrm{E}+13$ \\
\hline 110 & $3.8915 \mathrm{E}-8 \pm 3.0 \mathrm{E}-9$ & $1.5211 \mathrm{E}+0 \pm 7.5 \mathrm{E}-3$ & $1.1322 \mathrm{E}-1 \pm 2.2 \mathrm{E}-3$ & 0.2 & 0.9961 & $7.61 \mathrm{E}+12$ \\
\hline 120 & $4.6630 \mathrm{E}-8 \pm 2.4 \mathrm{E}-9$ & $4.1682 \mathrm{E}+0 \pm 1.4 \mathrm{E}-2$ & $1.6558 \mathrm{E}-1 \pm 2.9 \mathrm{E}-3$ & 0.2 & 0.9993 & $9.35 \mathrm{E}+11$ \\
\hline 130 & $1.4238 \mathrm{E}-6 \pm 1.2 \mathrm{E}-7$ & $10.025 \mathrm{E}+0 \pm 6.8 \mathrm{E}-2$ & $4.2075 \mathrm{E}-1 \pm 2.1 \mathrm{E}-2$ & 0.2 & 0.9984 & $9.59 \mathrm{E}+11$ \\
\hline 140 & 6.5538 E-4 \pm 4.9 E-5 & $31.609 \mathrm{E}+0 \pm 4.3 \mathrm{E}-1$ & $1.1512 \mathrm{E}+0 \pm 1.9 \mathrm{E}-1$ & 0.2 & 0.9994 & $7.32 \mathrm{E}+10$ \\
\hline$E a_{C L x} / \mathrm{kJ} \mathrm{mol}^{-1}$ & $206.2 \pm 21$ & $131.9 \pm 3.5$ & $97.8 \pm 9.2$ & & & \\
\hline $\operatorname{Lg}\left[Z_{C L x}\right] / \mathrm{d}^{-1}$ & $20.824 \pm 2.80$ & $18.137 \pm 0.47$ & $12.337 \pm 1.22$ & & & \\
\hline$R^{2} /-$ & 0.9899 & 0.9979 & 0.9743 & & & \\
\hline$S D^{2} /\left(\mathrm{d}^{-1}\right)^{2}$ & 0.128 & 0.0753 & 0.0511 & & & \\
\hline
\end{tabular}

Reaction rate constants and Arrhenius parameters for the intergrtaed HGR Q obtained with model 'Q: main: first order + autocatalytic; minor: exponential'; $\mathrm{Qe}=2730 \mathrm{~J} \mathrm{~g}^{-1}$, description range from 0 to $30 \mathrm{~J} \mathrm{~g}^{-1}$. Average of a $=0.0033$ with standard deviation of 0.0004

\section{Discussion}

The evaluation of characteristic times to events (bend in HGR curves and strong increase of CL-rate) showed good agreement. With these times the in-service time period can be determined, also at time-temperature profile loads [19]. In principle kinetic modelling of measurement data improves the applicability of the data because the prediction of in-service times is based on the recognized behaviour of the sample. In Fig. 6 the Arrhenius diagram of the three reaction rate constants of modelling the integrated $\mathrm{CL}$ rate and heat generation data are depicted. The models are approximate 
Fig. 6 Arrhenius diagram of the reaction rate constants obtained from the modelling of the integrated CL-rate (broken lines) and the heat generation (solid lines) of the HEC

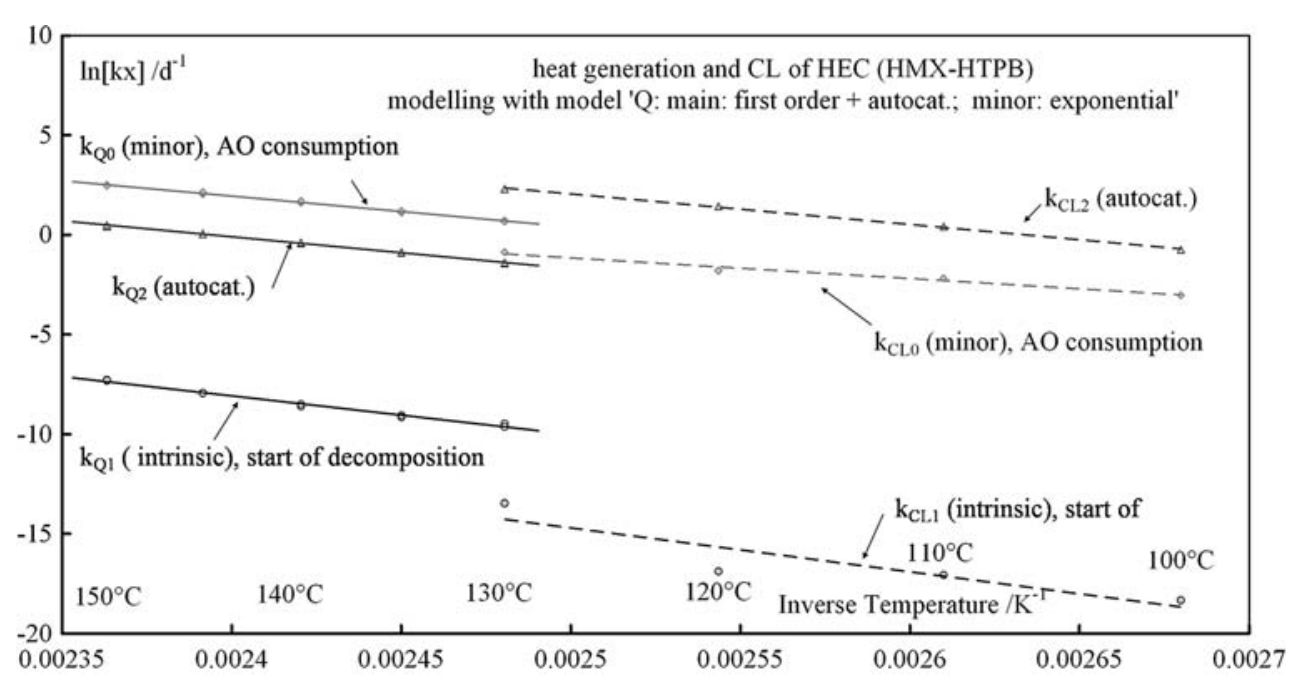

ones as already explained but nevertheless they allow some conclusions. In both modelling the autocatalytic rate constants are almost of the same value, $\mathrm{Ea}_{\mathrm{C} 2}=131.9 \pm$ $3.5 \mathrm{~kJ} \mathrm{~mol}^{-1}$ and $\mathrm{Ea}_{\mathrm{Q} 2}=133.3 \pm 2.4 \mathrm{~kJ} \mathrm{~mol}^{-1}$. This may indicate that in the autocatalytic case the radical type oxidation processes dominate and can be seen with heat generation as well as with Chemiluminescence. The oxidation can originate from oxygen and from $\mathrm{NO}_{2}$ which is formed by HMX decomposition.

Differences are found in the modelling of stabilizing reaction. Chemiluminescence sees oxidation processes in which the antioxidant is specifically involved. This type of resolution is not possible with heat generation rate which sums over all reactions going on. The activation energy $E a_{C o}$ of reaction rate $k_{C o}$ is seen as describing the antioxidant consumption during the action of the AO. The value of $E a_{Q o}$ of $k_{Q o}$ is definitely greater than the one of $E a_{C o}$. Underlying further processes as HMX decomposition interfere with the reaction heat caused by antioxidant consumption. But this value of $E a_{Q o}=128.4 \pm 2.7 \mathrm{~kJ} \mathrm{~mol}^{-1}$ agrees quite well with the activation energy $E a_{k d Q}=123.7 \pm 3 \mathrm{~kJ} \mathrm{~mol}^{-1}$ determined from the characteristic time to the sharp bend in the HGR curves. In both modelling the activation energies for the intrinsic reaction rate constants have high values. They are in the same range regarding the relatively high standard deviation in $E a_{C 1}=206 \pm 21 \mathrm{~kJ} \mathrm{~mol}^{-1}, E a_{Q 1}=$ $161 \pm 6 \mathrm{~kJ} \mathrm{~mol}^{-1}$. It seems that the reactions described by the first (intrinsic) model part and observed by Chemiluminescence change with temperature, which is not the case with the probing by heat generation rate. Also the approximate character of the model can cause such effects for $k_{C 1}$.

\section{Summary and conclusions}

A high explosive formulation based on HTPB bonded HMX was investigated with two high sensitivity methods: heat flow microcalorimetry, probing the net sum of all reaction heats and Chemiluminescence probing oxidative reaction by photon counting. In both measurement sets the characteristic changes in the curves correlate. They are attributed to the end of the action of the phenolic antioxidant used in the formulation to protect the HTPB binder. The times to these characteristic changes have nearly equal Arrhenius parameters. Both methods indicate strong autocatalytic decomposition reactions. The data could be described with an autocatalytic model extended by the stabilizing reaction for the antioxidant. It is approximate because more detailed models are not applicable with the information provided by the measurements. But they allow already some conclusions. The modelling revealed congruence in the autocatalytic part in both data sets. The first (intrinsic) part of the decomposition is probed differently by the two methods, which is disclosed by the modelling. The antioxidant reaction is directly recognized by Chemiluminescence whereas with heat generation some additional reaction seems to interfere.

\section{References}

1. Roduit B, Guillaume P, Wilker S, Folly P, Sarbach A, Berger B, et al. Advanced simulation of the lifetime of energetic materials based on HFC signals. HFCS-EM 2008;67-87.

2. Bohn MA, Pontius H, Hürttlen J. Characterisation and performance of advanced systems. Proceedings of the 38th International Annual Conference ICT EM, Karlsruhe 2007;4-18.

3. Bohn MA, Gerber P. Prediction of usetime of three nitrocellulose based propellants. Proceedings by GTPS, 2007;1:153-65.

4. Bohn MA. Thermal stability of hydrazinium nitroformate (HNF) assessed by heat generation rate and heat generation and mass loss. J Pyro Iss. 2007;26:65-94.

5. Bohn MA, Hartlieb K. Kinetic modelling of the heat generation of GUDN (guanylurea dinitramide, FOX 12). Proceedings by Fraunhofer ICT, Pfinztal 2008;339-77.

6. Pontius H, Bohn MA, Aniol J. Stability and compatibility of a new curing agent for binders applicable with ADN evaluated by 
heat generation rate measurements. Proceedings by Fraunhofer ICT, Pfinztal 2008;247-80.

7. Neumüller O-A, editor. Römpps Chemie-Lexikon. Franckh'sche Verlagshandlung, Stuttgart, 8th ed. 1979-1988.

8. Radziszewski B. Über das Leuchten des Lophins. Ber D Chem Ges. 1877;10:70.

9. Scheirs J. Compositional and failure analysis of polymers. Chichester: J. Wiley \& Sons; 2000.

10. Zlatkevich L. Chemiluminescence in evaluating thermal oxidative stability. J Polym Sci B Polym Phys. 1990;28:425-9.

11. Celina M, George G. A heterogeneous model for the thermal oxidation of solid polypropylene from chemiluminescence analysis. Polym Degr Stab. 1993;40:323-35.

12. Matisová-Rychlá L, Rychly J. Thermal oxidation of nonstabilized and stabilized polymers and chemiluminescence. J Polym Sci. 2004;42:648-60.

13. Lacey D, Dudler V. Chemiluminescence from polypropylene. Part 1. Imaging thermal oxidation of unstabilized film. Polym Degrad Stab. 1996;51:101-8.
14. Russel G. Deuterium-isotope effects in the autoxidation of aralkyl hydrocarbons. Mechanism of the interaction of PEroxy radicals. J Am Chem Soc. 1957;79:3871-7.

15. Vasiliev R. Prog React Kinet. 1967;4:305.

16. Pospíšil J, Horák Z, Pilař J, Billingham N, Zweifel H, Nešpůrek $S$. Influence of testing conditions on the performance and durability of polymer stabilisers in thermal oxidation. J Polym Degr Stab. 2003;82:145-62.

17. http://www.aclinstruments.com

18. Bohn MA. Kinetic description of mass loss data for the assessment of stability, compatibility and aging of energetic components and formulations exemplified with epsiv-CL20. Propellants Explos Pyrotech. 2002;27:125-35.

19. Origin Version 7.0 (German), SR 4, v7.0552.

20. Bohn MA, Natural Ageing of two seat belt gas generators. Proceedings 2nd IPASS by GTPS, Bordeaux 2007;145-62. 